\title{
Occupational Exposure to Impulse Noise Associated With Shooting
}

\author{
Felicja Lwow \\ Department of Health Promotion, University School of Physical Education in Wrocław, Poland
}

\author{
Paweł Jóźków \\ Marek Mędraś \\ Department of Sports Medicine and Nutrition, University School of Physical Education \\ in Wrocław, Poland
}

Shooting training is associated with exposure to a considerable amount of unique noise. We wanted to evaluate noise exposure during such training. Our observations especially apply to professional sport shooters, but they are also valid for shooting coaches/instructors. We collected acoustic signals in 10-, 25- and 50-m as well as open-air shooting ranges. The recorded material was analysed with orthogonal, adaptive parameterization by Shur. The mean duration of a single acoustic signal was 250-800 ms with the C-weighted sound peak pressure level of 138.2-165.2 dB. Shooters may be exposed to as many as 600-1350 acoustic impulses during a training unit. The actual load for the hearing organ of a professional shooter or a shooting coach is 200000 acoustic stimuli in a year-long training macrocycle. Orthogonal, adaptive parameterization by Shur makes safe scheduling of shooters' training possible.

weapon noise classification noise-induced hearing loss prevention

\section{INTRODUCTION}

A varying degree of hearing impairment is found in shooters. It is usually most evident at frequencies of 4 and $6 \mathrm{kHz}[1,2,3,4,5,6]$. Even a single exposure to weapon noise may induce permanent changes in the ear. It is characteristic that the risk of hearing loss is higher under exposure to impulse rather than permanent noise $[3,7,8,9,10,11,12,13,14,15]$.

Proper evaluation of acoustic conditions of shooting ranges should decrease the risk of permanent threshold shift in shooters. The specificity of the weapon noise depends on both the parameters of a single stimulus and the number and the time distribution of the impulses. Unfortunately, actual assessment and control of noise does not consider the specificity of shooting training. Occupational exposure recommendations (regarding 8-h, daily and weekly noise load) [16, 17, 18, 19, 20, 21] cannot be simply transferred to shooting. For example, in professional sport shooters and in shooting coaches, a full training macrocycle should be considered as the actual load for the hearing organ.

Our aim was to evaluate the exposure to weapon noise in shooters during training and competitions.

\section{MATERIAL AND METHODS}

Our study was performed in a complex of four shooting ranges: $10 \mathrm{~m}$ (pneumatic weapon), $25 \mathrm{~m}$, $50 \mathrm{~m}$ and an open-air one. They were used for competitions in the shotgun, the rifle, the pistol and the running-target events.

Correspondence and requests for offprints should be sent to Felicja Lwow, Department of Health Promotion, University School of Physical Education in Wrocław, ul. Rzeźbiarska 4, 51-629 Wrocław, Poland. E-mail: <felicitas1@wp.pl>. 
Acquisitions of acoustic signals were carried out with a 2230 Brüel\&Kjær (Denmark) sound level meter with adapters preventing false steering of signals exceeding $140 \mathrm{~dB}$. The device was connected to a 16-bit A/C transformer working at the speed of 44100 samples per second. Records were made for several types of weapons and ammunition. Among them were pistols .22 LR Baikal MCM Margolin (Izhevsky Mekhanichesky Zavod, USSR); central ignition CZ 75 Kadet (Česká zbrojovka, Czechoslovakia); .38 special ZKR 551 (Zbrojovka Brno, Czechoslovakia); 7.62 $\mathrm{mm}$ TT (Łucznik, Poland); $5.6 \mathrm{~mm}$ rapid-fire Walther (Carl Walther Waffenfabrik, Germany) and $9 \mathrm{~mm}$ Hämmerli standard 208 (Hämmerli, Switzerland). Ammunition comprised $5.6 \mathrm{~mm}$ (extra 75, R50); $9 \mathrm{~mm}$ Parabellum regular (Lapua, Finland), $9 \mathrm{~mm}$ Parabellum (Lapua, Finland); Combat $9 \mathrm{~mm}$ Parabellum (Mesko, Poland) and .38 special (Norma $\mathrm{GmbH}$, Germany); 7.62 Tokarev.

The acoustic environment was assessed indoors and outdoors during individual and group training (4 or 6 shooters). Measurements were also carried out during a competition with 32 shooters. The microphone was located $2 \mathrm{~m}$ from the shooting stand.

Acoustic signals were recorded in five selected shooting stands (to eliminate indoor acoustic artifacts). We recorded 10 impulses for each type of weapon and ammunition with the microphone placed at the height of the sport shooters' ears. Measurements were also taken at the referee stand and in the audience area.

In the case of the rapid-fire pistol, four series were recorded in the shooting stand (five shots in $8 \mathrm{~s}$, five shots twice in $8 \mathrm{~s}$, five shots twice in $6 \mathrm{~s}$, five shots twice in $4 \mathrm{~s}$ ) and two series in two different stands in the audience (five shots in $4 \mathrm{~s}$ ).

We also evaluated acoustic noise during group training (sport and central ignition pistol) and shooting competitions. During 1.5 -h group training with four stands occupied six records of acoustic waveforms were made. The following weapons were used: central ignition $\mathrm{CZ} 75$ Kadet (ammunition: $9 \mathrm{~mm}$, Parabellum, Lapua, Finland); Bersa A 23 from Bersa, Argentina (ammunition: $9 \mathrm{~mm}$, Parabellum, Lapua, Finland) and Glock 19 from Glock, Austria (ammunition:
$9 \mathrm{~mm}$, Parabellum, NIKE-FIOCCHI, Hungary). Measurements were repeated for other shooting stands.

Another set of records was made during group training. The following sport pistols were used at eight shooting stands: Hämmerli standard 208 (ammunition: $9 \mathrm{~mm}$, Parabellum, Lapua, Finland), sport MCM Margolin (ammunition: 5.6 $\mathrm{mm}$, extra 75) and Walther Olimpia (ammuntion: $5.6 \mathrm{~mm}, \mathrm{R} 50$ ). Four measurements were made during 1.5-h training units (rotating the place of sound acquisition).

We monitored acoustic noise during a shooting competition in a $25-\mathrm{m}$ indoor range with 32 occupied stands (16 sport pistols, 16 central ignition). Each competitor fired 10 times in $10 \mathrm{~min}$. Acquisitions were made three times in selected areas of the indoor range (middle, extreme left and extreme right side). Because of regulations the measurements were performed 2 and $4 \mathrm{~m}$ from the shooting stands. This procedure was repeated twice in three selected groups of competitors. Background noise in the building did not exceed $56 \mathrm{~dB}$.

Records were also made for individual outdoor training in trap (FN Browning cal 12, USA; ammunition: Olimpic 24 trap, Fam-Simadex, Poland; B-12 Bock shotgun, USA; ammunition: skeet, NIKE-FIOCCHI, Hungary). The records were analysed using probabilistic characteristics of the resultant signal (compiled from random signals emitted by $N$ sources at random times) reaching the sensor in a specific point of the acoustic field. Impulse signals in shooting sports are not stationary and their probabilistic characteristics change at random time points.

We analysed the recorded material with orthogonal, adaptive Shur parameterization. This method makes it possible to describe in detail several features of acoustic signals: duration, time/ frequency structure and changes in power spectral density. An extensive description of this method has been published elsewhere [22, 23, 24].

We estimated the number of acoustic signals reaching shooters' ears in selected training cycles.

\section{RESULTS}

In our measurements the mean duration of a single acoustic signal was $250-800 \mathrm{~ms}$. The 
$C$-weighted sound peak pressure level was 138.2-165.2 dB (depending on the type of weapon and ammunition). Figure 1 presents a typical time history of an acoustic signal.

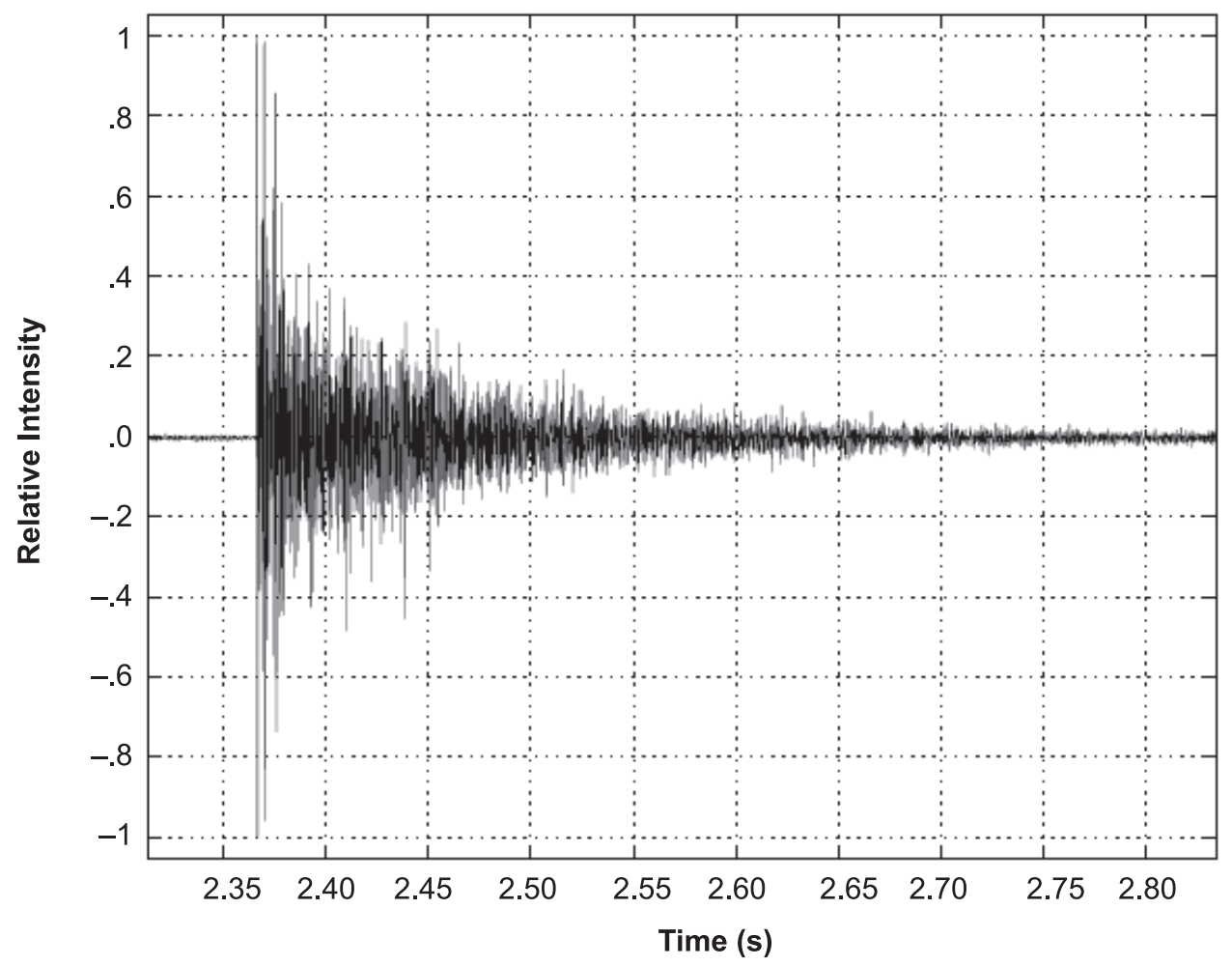

Figure 1. Time history of an acoustic signal (relative intensity = maximal sound pressure/temporary sound pressure). Notes. Weapon: Hämmerli (Hämmerli, Switzerland); 25-m shooting range.

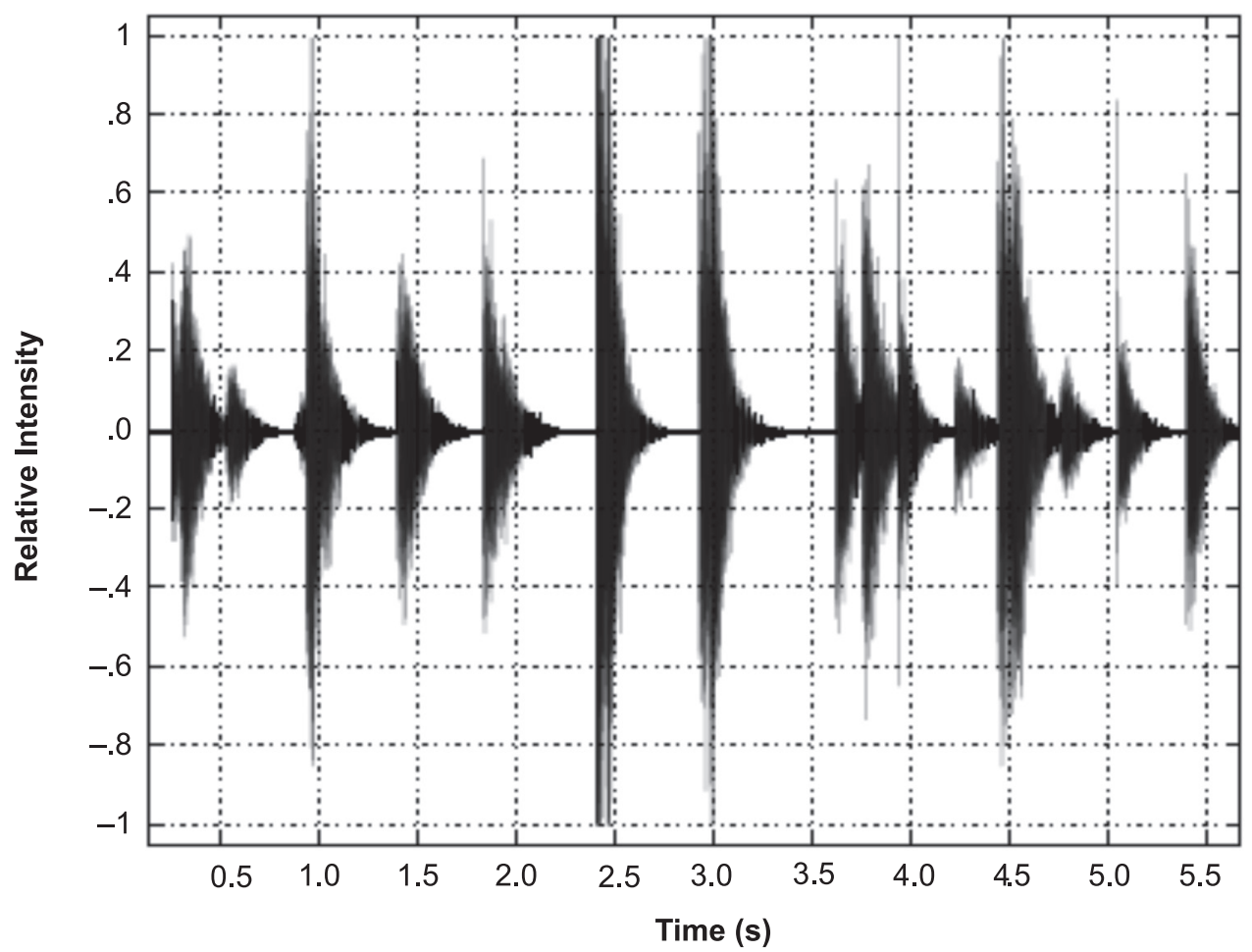

Figure 2. Acoustic signals (relative intensity = maximal sound pressure/temporary sound pressure. Notes. Competition; 25-m shooting range; 32 competitors. 
After an analysis of the duration and the time/ frequency structure of signals we assumed that the time structure of a specific signal could be modified in 3-5 ms. Impulses that appeared in intervals longer than $3-5 \mathrm{~ms}$ could be treated as separate ones. In accordance with the regimens of shooting competitions consecutive signals appeared in intervals of 100-150 ms (Figure 2).

An acoustic signal impacts the ear in the first 3-5 ms, though its total duration is much longer. Apart from the time structure, the signal can also be characterized by effective duration, changes in power spectral density (Figure 3 ) and transient acoustic power (Figure 4). We observed that an initial wide spectrum characteristic of a signal narrowed after $1 \mathrm{~ms}$ (Figure 3).

After the first $1 \mathrm{~ms}$ the level of acoustic power decreased by $30-70 \mathrm{~dB}$ (starting from 138-165 $\mathrm{dB}(C)$, depending on the type of weapon). After the next 3-5 $\mathrm{ms}$ the power level was lower than the initial value by $90 \mathrm{~dB}$ (Figure 4). Thus, the highest effective level of acoustic power was expected between 1 and $2 \mathrm{~ms}$ depending on the shooting event.

Another important parameter in evaluating exposure to noise is the time/frequency structure of signals. Figure 3 illustrates a typical example of changes (fluctuations) in power spectral density for the Margolin pistol.

In the case of the Margolin pistol the signal is broadband at first, but after $0.5 \mathrm{~ms}$ several components disappear. In this period $(0.5 \mathrm{~ms})$ the power of the spectrum decreases by $50 \mathrm{~dB}$ when compared with baseline. The results are similar for other disciplines and weapons (data not presented). In the period between the 3rd and 5th $\mathrm{ms}$ the power of the spectrum decreases by up to $90 \mathrm{~dB}$. It is characteristic that low- and middlefrequency components (up to $6 \mathrm{kHz}$ ) are most important for these impulses.

In addition to the parameters of a single impulse, the ototraumatic effects of impulse noise also depend on the number of signals that reach the hearing organ. We estimated that an individual shooter may be exposed to as many as 200000 acoustic stimuli in a year-long training macrocycle. In our records, members of Poland's national shooting team were exposed to 19860 impulses (of $149 \mathrm{~dB}$ ) prior to the Olympic Games in Sydney, Australia, in 2000 (in which the team won a gold medal). This number was calculated from 90-min training sessions with 125 fired shots (according to our observations and personal communication with the coach). However, we have to note here that shooters

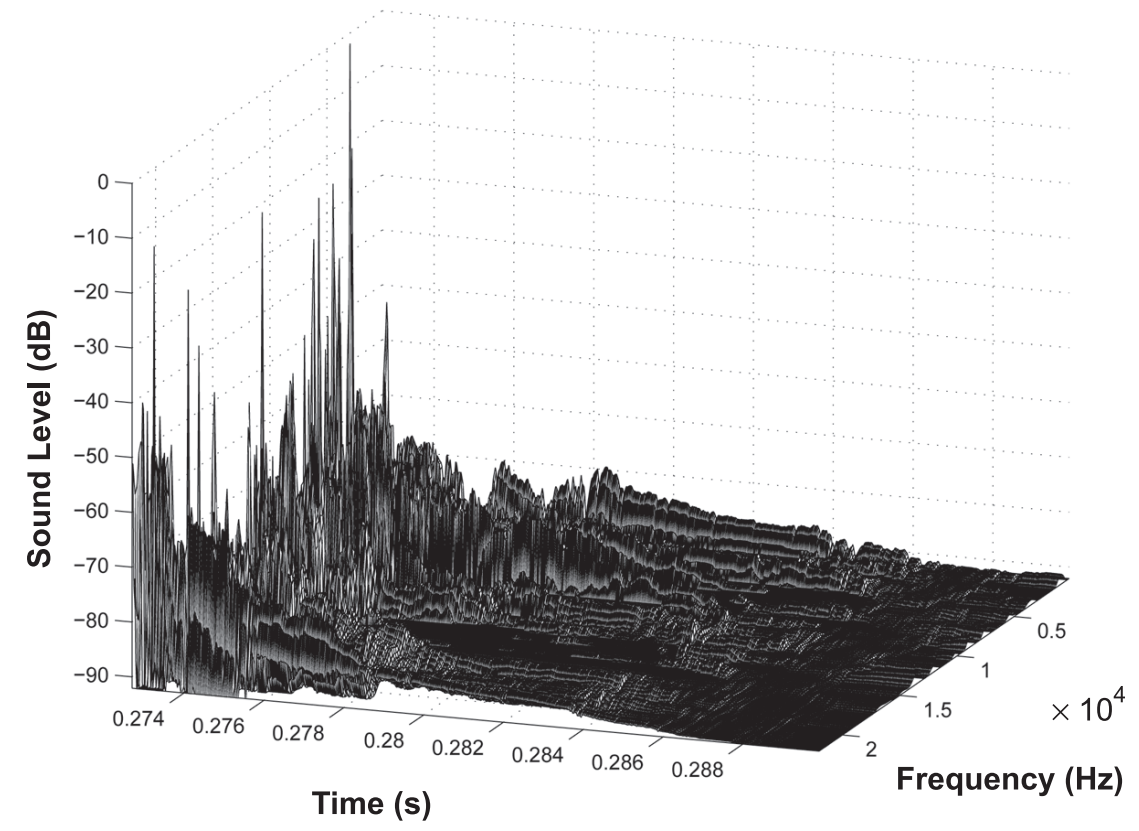

Figure 3. Changes in power spectral density. Notes. In this graph $0 \mathrm{~dB}=138 \mathrm{~dB}$ of sound pressure; weapon: Margolin (Izhevsky Mekhanichesky Zavod, USSR); 25-m shooting range. 


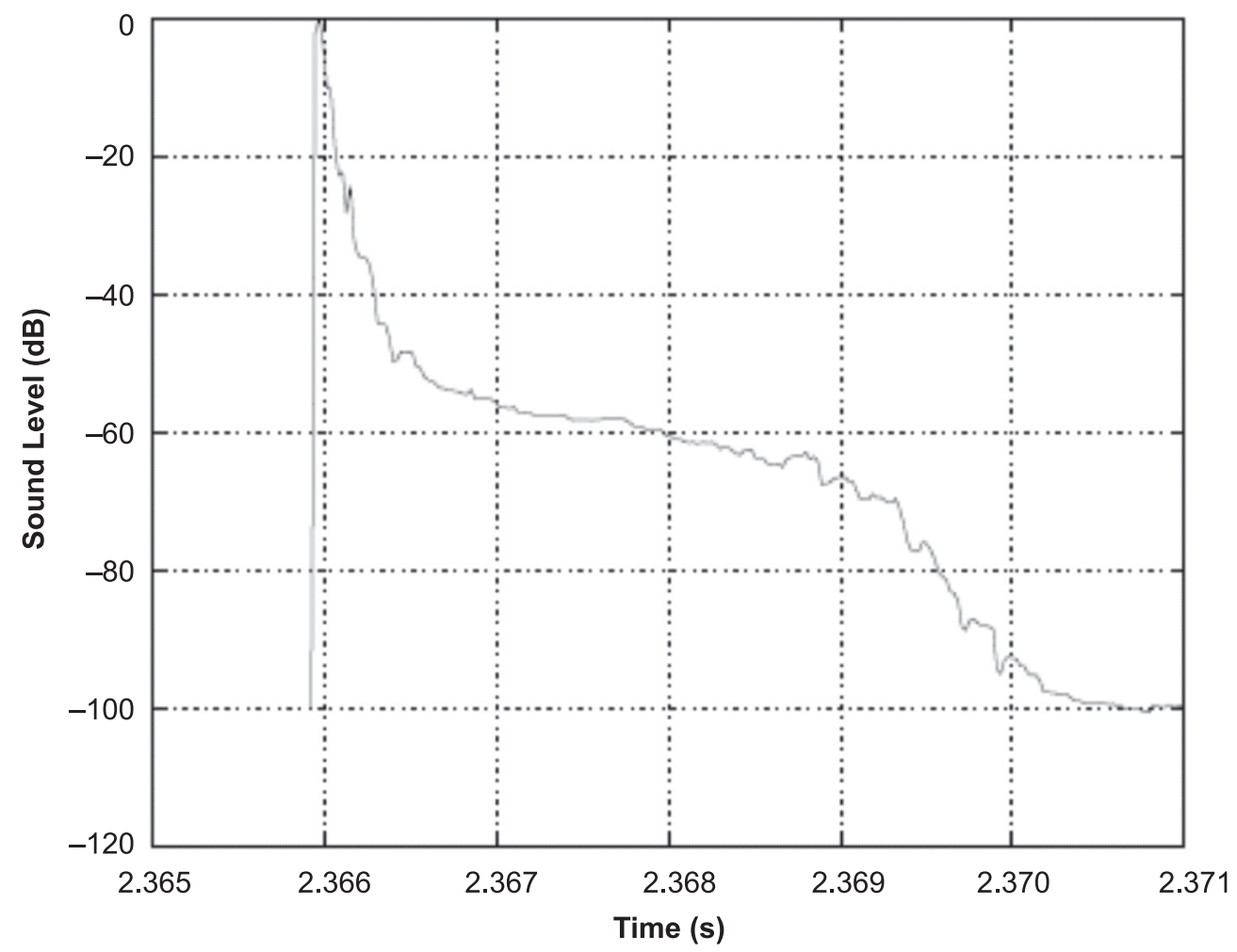

Figure 4. Changes in transient acoustic power. Notes. In this graph $0 \mathrm{~dB}=165.2 \mathrm{~dB}(C)$ of sound pressure; weapon: Hämmerli (Hämmerli, Switzerland); 25-m shooting range.

often practise in groups of 3-9. Thus, they may be exposed to as many as 600-1350 acoustic impulses during a training unit. This results in the main difference between exposure to permanent noise and exposure to impulse noise of shooters and shooting coaches.

\section{DISCUSSION}

Several authors have suggested that the middle ear's ability to prevent acoustic damage is low [7, $8,9,10,21,25,26]$. Previous descriptions of the risk for the hearing organ were based on intuition rather than on measurable parameters [7, 25]. The orthogonal, adaptive parameterization by Shur is a method that makes a detailed description of actual exposure to impulse noise possible [22, 23, 24]. It covers several features of acoustic signals such as the time structure, changes in power spectral density and changes in the level of transient power.
Muscle jerks play an important role in increasing the acoustic impedance of the ear $[9,13,27]$. Attenuation of acoustic energy (muffling), which depends on the acoustic impedance of the ear, is most effective in the range between 500 and $4000 \mathrm{~Hz}$ and reaches the values of $25-30 \mathrm{~dB}[26,28,29]$.

The reaction of middle-ear muscles to acoustic impulse signals plays a key role in the defense system of the ear. The reaction time of a muscle comprises latency, duration of the maximal contraction and relaxation time. Those features are related to types of impulses and the duration of stimulation. In view of our results, we suppose that low- and middle-frequency components significantly affect the hearing organ and lead to pathological changes in the ear.

The method we used describes the time structure of signals. It makes it possible to simulate the exposure of the ear in relation to hypothetical jerk reaction times. For the stapes muscle a jerk is induced in 10-200 ms. It lasts $1 \mathrm{~s}$ and the relaxation time is between $200 \mathrm{~ms}$ and 
$2 \mathrm{~s}$ (in some instances up to $180 \mathrm{~s}$ ). For the tensor muscle of tympanic membrane these parameters are, respectively, $17 \mathrm{~ms}$ (full tension after 100-200 ms), $1 \mathrm{~s}$ and 1-2 s [9, 25, 28, 30].

During shooting training (and competitions) the effective duration of an acoustic stimulation is $2-5 \mathrm{~ms}$. As middle-ear muscles react after 100-200 ms, a significant part of energy is passed to the inner ear without physiological suppression. That is why the first impulse may have the greatest impact, as it reaches receptors before muscle jerks are triggered. In shooters who fire their own weapon it is probable that the jerk of the tensor muscle of tympanic membrane is triggered earlier [29]. Theoretically, this situation is also possible during group training. A complete contraction may increase the tension of muscles fourfold and thus increase the acoustic impedance of the ear.

Standard training of an individual shooter consists of 150-200 shots fired in $90 \mathrm{~min}$. Consecutive impulses appear on average every $27000 \mathrm{~ms}$. Long-term exposure to impulse noise results in adaptation, physiological fatigue (longer reaction time and no contraction of intraear muscles), eventually decreasing acoustic impedance and the defensive abilities of the ear. During group training the number of impulses may increase even sixfold and significantly decrease defensive reactions of the ear muscles. Consecutive impulses may arrive during the phase of muscle activation. This is relatively safe as the muscles are totally contracted. If the next signal appears during the relaxation phase the contraction reaction is still faster than if the ear had not been prepared. An impulse arriving during physiological fatigue may lead to a pathological response and cause permanent change in the hearing threshold.

Under conditions typical for a competition, acoustic impulses appear in intervals of 100-150 ms (minimum) and 300-500 ms (maximum). When compared with 1-s middleear muscle jerks, this means that every signal is attenuated before it is transmitted to the inner ear. The situation is similar if an impulse comes when the muscle is relaxed (200 ms to $2 \mathrm{~s}$, sometimes $180 \mathrm{~s}$ ). The number of impulses can reach 15 in $5 \mathrm{~s}, 180$ in $1 \mathrm{~min}$ and 16200 (all stands occupied) in one training session of $90 \mathrm{~min}$. The $C$-weighted sound peak pressure level varies from 138 to $165 \mathrm{~dB}(C)$ depending on the competition and the type of weapon.

There are $\sim 13000$ acoustic signals in a training microcycle (7-8 days), $\sim 52000$ in a mezocycle (3-4 weeks) and 200000 signals in a macrocycle (one year). That is professional shooters' and shooting coaches' load. This number of stimuli leads to physiological fatigue and an eventual decrease in the effectiveness of the attenuation of impulse energy (by 20-30 dB). If periods of rest between training sessions are shorter than $16 \mathrm{~h}$, especially if the same weapon and ammunition are used, it is highly probable that the hearing organ will be damaged. Exposure to impulse noise usually affects the frequency range between 2 and $6 \mathrm{kHz}$, which is protected mainly by the mechano-acoustic system of the middle ear $[2,4,6,13,26]$. Some shooters do not suffer from hearing impairment probably due to their individual resistance [27, 28]. It is well-known that exposure to noise closely depends on the shooting discipline and the features of a particular weapon $[1,3,5,6$, $11,31,32]$. However, in our opinion, the most important parameters to be considered while evaluating shooters' exposure to noise is the time distribution of impulses and the frequency with which they are repeated.

In rapid-fire competitions, shooters fire five times in 4, 6 and $8 \mathrm{~s}$ (Figure 5). An impulse with a $C$-weighted sound peak pressure level of $165.2 \mathrm{~dB}(C)$ appears every $400-1000 \mathrm{~ms}$ (shooters have to fire five times in 4,6 and $8 \mathrm{~s}$, standing next to one another during group training).

Ear-plugs decrease noise by $10-38 \mathrm{~dB}$, depending on the frequency of the sources of noise [31, 32, 33, 34, 35, 36, 37]. An impulse may come during muscle reaction or during relaxation. If relaxation lasts $200 \mathrm{~ms}$, stimuli appearing in intervals of $400 \mathrm{~ms}$ may arrive while the protective mechanisms of the ear are switched off. If muscle relaxation lasts $180 \mathrm{~s}$, every impulse comes during the phase of adaptation. If an impulse reaches the ear after 


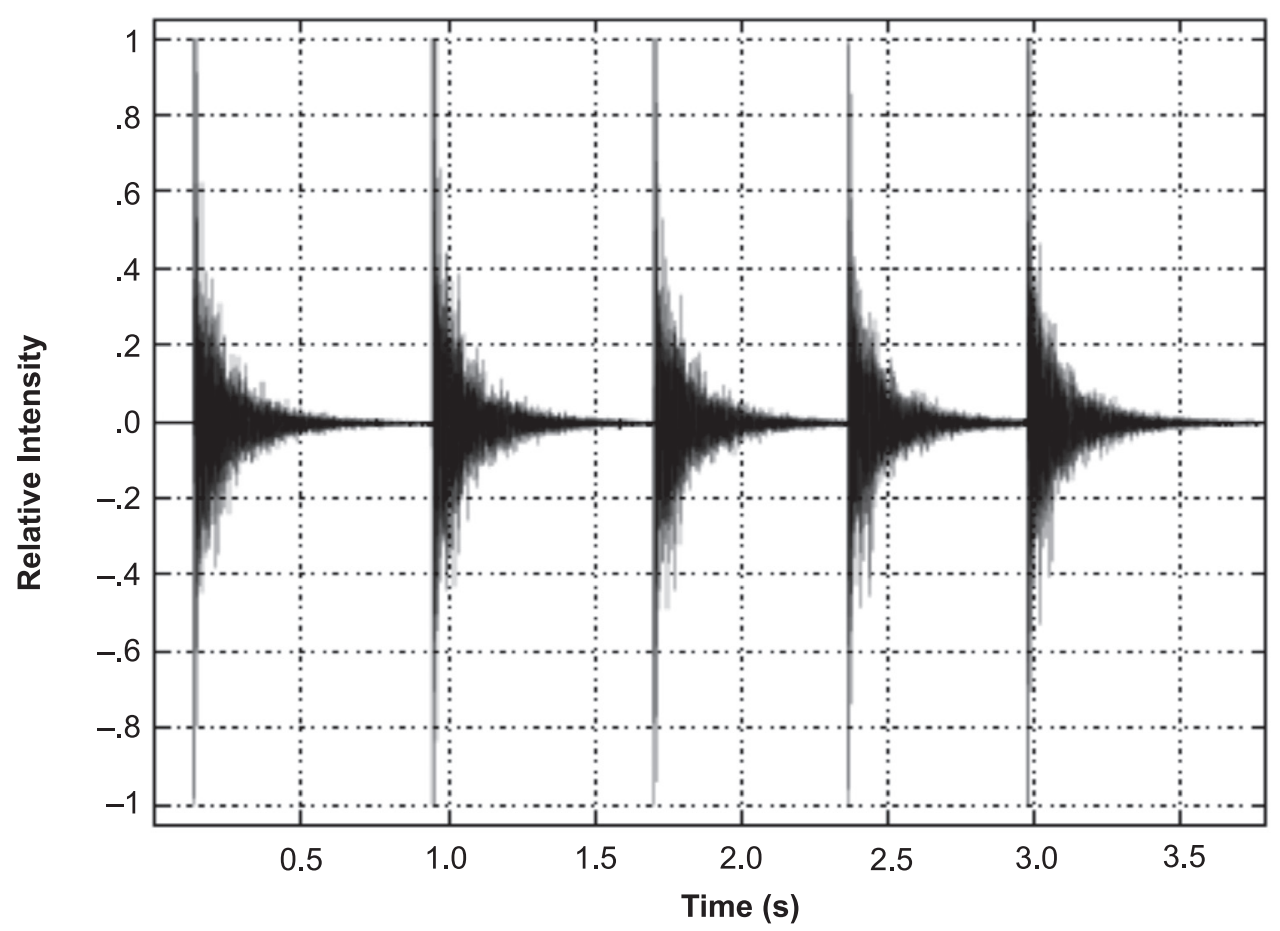

Figure 5. Acoustic signals (relative intensity = maximal sound pressure/temporary sound pressure). Notes. Weapon: Hämmerli (Hämmerli, Switzerland); 25-m shooting range.

$200 \mathrm{~ms}$, the next impulse evokes a muscle jerk. Ototraumatic effects of shooting noise are caused by impulses arriving while the jerks of intraear muscles are disabled. Thus, ear trauma is determined by the time distribution of impulses.

Our analysis opens a new approach towards assessing impulse noise during shooting.

\section{CONCLUSIONS}

- Orthogonal, adaptive parameterization by Shur makes it possible to analyse the time structure, changes in power spectral density and changes in the transient power of acoustic signals.

- The duration of impulse acoustic signals in sport shooting is $250-800 \mathrm{~ms}$ (depending on the discipline). The time structure of the signal is modified in $3-5 \mathrm{~ms}$, which is crucial for ear protection. Acoustic impulse signals can be analysed separately as long as they occur over $5 \mathrm{~ms}$ apart (in our study the difference was $100-150 \mathrm{~ms})$. Changes in power spectral density take place between the 3rd and 5th ms and maximal transient acoustic power is present for $1-2 \mathrm{~ms}$.
- Those parameters together with the sound peak level objectively describe acoustic impulse signals in sport shooting. They can be used to assess the effectiveness of the defense mechanisms of the hearing organ in shooters.

\section{REFERENCES}

1. Kryter KD. Effects of nosocusis, and industrial and gun noise on hearing of U.S. adults. J Acoust Soc Am. 1991;90(6):3196-201.

2. Price GR, Kim HN, Lim DJ, Dunn D. Hazard from weapons impulses: histological and electrophysiological evidence. J Acoust Soc Am. 1989;85(3):1245-54.

3. Pekkarinen J, Iki M, Starck J, Pyykko I. Hearing loss risk from exposure to shooting impulses in workers exposed to occupational noise. Br J Audiol. 1993; 27(3):175-82.

4. Price GR. Predicting mechanical damage to the organ of Corti. Hear Res. 2007; 226(1-2):5-13. 
5. Thompson IL. Gun noise, its nature and effects. Australian Shooters Journal. 1992; 20:87-9.

6. Rylander R, Lundquist B. Annoyance caused by noise from heavy weapon shooting ranges. J Sound Vibrat. 1996; 192(1):199-206.

7. Counter SA, Borg E, Olofsson A. Ototraumatic effects of computer simulated magnetic coil impulse noise: analysis of mechanisms. Acta Otolaryngol. 1993;113 (6):699-705.

8. Hamernik RP, Ahroon WA, Hsueh KD. The energy spectrum of an impulse: its relation to hearing loss. J Acoust Soc Am. 1991;90(1):197-204.

9. Henselman LW, Henderson D, Subramaniam M, Sallustio V. The effect of "conditioning" exposures on hearing loss from impulse noise. Hear Res. 1994;78(1):1-10.

10. Starck J, Toppila E, Pyykko I. Impulse noise and risk criteria. Noise Health. 2003; 5(20):63-73.

11. Paakkonen R, Lehtomaki K. Protection efficiency of hearing protectors against military noise from handheld weapons and vehicles. Noise Health. 2005;7(26):11-20.

12. Tambs K, Hoffman HJ, Borchgrevink HM, Holmen J, Engdahl B. Hearing loss induced by occupational and impulse noise: results on threshold shifts by frequencies, age and gender from the Nord-Trondelag Hearing Loss Study. Int J Audiol. 2006;45(5):309-17.

13. Price GR. Validation of the auditory hazard assessment algorithm for the human with impulse noise data. J Acoust Soc Am. 2007;122(5):2786-802.

14. Chan PC, Ho KH, Kan KK, Stuhmiller JH, Mayorga MA. Evaluation of impulse noise criteria using human volunteer data. J Acoust Soc Am. 2001;110(4):1967-75.

15. Rice CG. Human response effects of impulse noise. J Sound Vibrat. 1996;190(3): 525-43.

16. Lusk SL. Noise exposures. Effects on hearing and prevention of noise induced hearing loss. AAOHN J. 1997;45(8): 397-408; quiz 409-10.

17. McNamee R, Burgess G, Dippnall WM, Cherry N. Predictive validity of a retrospective measure of noise exposure. Occup Environ Med. 2006;63(12):808-12.

18. Prince MM, Gilbert SJ, Smith RJ, Stayner LT. Evaluation of the risk of noiseinduced hearing loss among unscreened male industrial workers. J Acoust Soc Am. 2003;113(2):871-80.

19. Daniell WE, Swan SS, McDaniel MM, Camp JE, Cohen MA, Stebbins JG. Noise exposure and hearing loss prevention programmes after 20 years of regulations in the United States. Occup Environ Med. 2006;63(5):343-51.

20. Turkkahraman S, Gok U, Karlidag T, Keles E, Ozturk A. Findings of standard and high-frequency audiometry in workers exposed to occupational noise for long durations. Kulak Burun Bogaz Ihtis Derg. 2003;10(4):137-42. In Turkish.

21. Fausti SA, Wilmington DJ, Helt PV, Helt WJ, Konrad-Martin D. Hearing health and care: the need for improved hearing loss prevention and hearing conservation practices. J Rehabil Res Dev. 2005; 42(4 Suppl 2):45-62.

22. Dewilde P, Dym H. Shur recursions, error formulas and convergence of rational estimators for stationary stochastic processes. IEEE Transon IT. 1981(27):446-61.

23. Dewilde P. A course on the algebraic Shur and Nevanlinna-Pick interpolation problems. In: Deprettere A, editor. Algorithms and parallel VLSI architectures. London, UK: Elsevier; 1991. p. 13-70.

24. Lee DTL, Morf M, Friedlander B. Recursive least-squares ladder estimation algorithms. IEEE Trans on CAS. 1981(28): 467-81.

25. Ferber-Viart C, Soulier N, Dubreuil C, Duclaux R. Cochleovestibular afferent pathways of trapezius muscle responses to clicks in human. Acta Otolaryngol. 1998; 118(1):6-10.

26. Zwislocki J. Analysis of middle ear function. Part I. Input impedance. J Acoust Soc Am 1996;34:1514-23.

27. Zheng XY, McFadden SL, Ding DL, Henderson D. Cochlear de-efferentation and impulse noise-induced acoustic trauma in the chinchilla. Hear Res. 2000;144 (1-2):187-95. 
28. Onusko E. Tympanometry. Am Fam Physician. 2004;70(9):1713-20.

29. Uchida $Y$, Nomura $H$, Itoh A, Nakashima $T$, Ando F, Niino N, Shimokata H. The effects of age on hearing and middle ear function. $\mathrm{J}$ Epidemiol. 2000;10(1 Suppl):S26-32.

30. Henderson D, Subramaniam M, Gratton MA, Saunders SS. Impact noise: the importance of level, duration, and repetition rate. J Acoust Soc Am. 1991;89(3):1350-7.

31. Paakkonen R, Lehtomaki K, Savolainen S, Myllyniemi J, Hamalainen E. Noise attenuation of hearing protectors against heavy weapon noise. Mil Med. 2000; 165(9):678-82.

32. Ylikoski M, Pekkarinen JO, Starck JP, Paakkonen RJ, Ylikoski JS. Physical characteristics of gunfire impulse noise and its attenuation by hearing protectors. Scand Audiol. 1995;24(1):3-11.
33. Abel SM, Odell P. Sound attenuation from earmuffs and earplugs in combination: maximum benefits vs. missed information. Aviat Space Environ Med. 2006;77(9):899-904.

34. Paakkonen R, Lehtomaki K, Myllyniemi J. Ear plug fit and attenuation-an experimental study. Acta Acustica united with Acustica. 2000;86:481-4.

35. Paakkonen R, Savolainen S, Myllyniemi J. Noise attenuation of hearing protectors in the human ear-a method description. Acta Acustica united with Acustica. 2000; 86:477-80.

36. Toivonen M, Paakkonen R, Savolainen S, Lehtomaki K. Noise attenuation and proper insertion of earplugs into ear canals. Ann Occup Hyg. 2002;46(6):527-30.

37. Zera J. The measurement of impulse noise protection by earmuffs [abstract]. J Acoust Soc Am. 2000;108(5):2621. 